the majority of volunteer physicians responding to incident scenes are unfamiliar with appropriate medical care provision in the out-of-hospital setting and that they do not usually appreciate the operational responsibilities of the jurisdictional authorities. As a result, it is felt that volunteer physicians generally inhibit operations more than they help during a multi-casualty incident (MCI), particularly in the modern urban setting. On the other hand, in municipalities where physicians regularly participate in field operations as part of the day-to-day emergency medical services (EMS) system, the incident command, including triage and scene management, appear to operate smoother during major incidents. This observation is not surprising in that it closely follows the first major rule of incident management, namely to follow day-to-day routines as closely as possible or else prospectively modify those daily routines to meet the potential needs of a major incident. The National Association of EMS Physicians (NAEMSP) is a recently-developed organization which provides a network for physicians who are legally responsible for prehospital medical care delivery and includes most of the designated medical directors for most major municipalities within the United States. The majority of these EMS physicians are familiar with the unique problems and logistics of the prehospital environment as well as the operational activities of the local civil authorities. Many regularly interact with the civil authorities on a routine basis in difficult emergency operations and can be prospectively recognized and trained as part of a disaster or MCI plan, whether at a local level or as part of a national network. Among its various activities, the organization has begun to provide routine discussions and reports on MCI management at its meetings and now plans to formally learn about major incidents whenever they occur in order to further educate its membership. It also is willing to assist the WAEDM in providing another centralized base of knowledge, as well as a clearinghouse for MCI research activities. Furthermore, the NAEMSP is even willing to provide an available pool of "street-wise" and capable physicians for assistance in major incidents. The overall goals and current activities of this organization will be discussed.

\section{MEDICAL RESPONSE TO TERRORIST INCIDENTS}

\author{
John P. Sullivan, M.A., Jersey City, \\ New Jersey, U.S.A.
}

Terrorist incidents are of increasing concern to the emergency medical community since they have the capability to produce the loss of life and casualties on a large scale. The mass casualties which may result from terrorist attack have the potential to overwhelm existing levels of response. Since all EMS personnel are potential responders to terrorist incidents, an understanding of the nature of terrorism and the types of injuries it can produce are essential. The nature of terrorist assault may require the development of specially trained Medical Response Teams for Terrorism. These teams, with their specialized training and skills, in cooperation with other agencies can form the basis of an appropriate medical response to terrorist incidents.

\section{PREHOSPITAL CARE EXPERIENCE IN MEXICO}

\author{
A. Grife, M.D., A. Zamudio, M.D., \\ R. Garccia-Morales, M.D., M. Gomez-Palacio, \\ M.D. and A. Rodriguez, M.D., \\ Mexico City, Mexico
}

Cruz Roja Mexicana Hospital is one of the largest institutions dedicated to the care of medical and surgical emergencies in Mexico City. Established in September, 1981, it conducted the first training course for pre-hospital care providers at the basic life support level in the country. In Mexico City with a population of $16,000,000$, trauma is the second cause of death in the age group of major productivity. Despite the deficient technical and economical facilities it was imperative to organize such a training program.

\section{Materials and Methods}

From January, 1982, to June, 1983, 1,437 paramedic interventions were performed; 1,428 $(99.37 \%)$ patients were transported by ambulances, 9 $(0.62 \%)$ patients were transported by helicopter, the average age of the patients was $32 ; 1,184(82.39 \%)$ were trauma victims and $221(15.38 \%)$ were medical emergencies, while $836(58.1 \%)$ were victims of blunt trauma and $317(22.05 \%)$ penetrating trauma. Other 